\title{
Who Seeks Treatment for Dual Disorders? Observations from a Dual Disorder Clinic at the National Drug Dependence Treatment Centre in India Over a 12 Year Period
}

\author{
Yatan Pal Singh Balhara, ${ }^{1}$ Siddharth Sarkar,, ${ }^{1,}$ Sagar Chandra Bera, ${ }^{1}$ Rishi Gupta, ${ }^{1}$ Nishtha Chawla, ${ }^{1}$ and \\ Rakesh Lal ${ }^{1}$ \\ ${ }^{1}$ Department of Psychiatry, National Drug Dependence Treatment Centre (NDDTC), All India Institute of Medical Sciences (AIIMS), New Delhi, India \\ "Corresponding author: Siddharth Sarkar, Department of Psychiatry, National Drug Dependence Treatment Centre (NDDTC), All India Institute of Medical Sciences (AIIMS), \\ New Delhi, India. E-mail: sidsarkar22@gmail.com
}

Received 2015 August 17; Accepted 2016 January 23.

\begin{abstract}
Background: There is limited literature available on the diagnosis and treatment of dual disorders in non-western settings. Objectives: The present study aims to describe the profile of patients diagnosed at a dual disorders clinic over a period of 12 years. Patients and Methods: This retrospective study analyzed the case records of patients registered in the dual diagnosis clinic of the national drug dependence treatment centre (NDDTC) in Ghaziabad. Information relating to the demographics of the sample, substance use disorders, and psychiatric disorders were extracted from the case records. The association between the use of specific substances and psychiatric illnesses was assessed.

Results: The study included 492 patients, the majority of whom were male, married, and employed. Psychotic disorders were the largest category among the comorbid psychiatric disorders (38.7\%), followed by depressive disorders (27.5\%), and bipolar disorders (20.0\%). Among the patients with primarily psychotic disorders, $40.8 \%$ were deemed to have substance-induced psychosis. Cannabis use had greater odds of being associated with psychotic disorders, opiates and benzodiazepines with depressive disorders, and alcohol with anxiety disorders.

Conclusions: The establishment of a dual diagnosis clinic offers an opportunity to gain further insights into the characteristics of patients diagnosed with dual disorders. It may also offer opportunities for training health-care personnel, evaluating specific treatment approaches, and providing comprehensive services customized to the patients' needs.
\end{abstract}

Keywords: Diagnosis, Dual (Psychiatry), Psychotic Disorders, Substance-Related Disorders, Cannabis, Mental Disorders

\section{Background}

Substance use disorders (SUD) often tend to co-occur with other psychiatric disorders (1-3). This co-morbidity, also referred to as a "dual disorder," has implications for the management and prognosis of these individuals $(4,5)$. The outcome of patients with dual disorders has been reported to be poorer as compared to that of patients with only SUD (6). The management of patients with dual disorders is limited not only by the constraints on pharmacological options but also because of the limited engagement and participation of these individuals in the therapeutic process $(7,8)$. Additionally, the co-occurrence of SUD with psychiatric disorders necessitates changes in the approach to the patients with respect to management strategies for treating their conditions (9-11). Hence, treatment services need to be geared towards the specific requirements of patients with dual disorders.

\section{Objectives}

Dual disorder clinics offer a potential opportunity to provide comprehensive integrated care to patients with co-morbid SUD and psychiatric disorders in the deaddiction treatment facility itself (12). The care provided by such clinics may be a viable option in resource-constrained settings where the implementation of more intensive models of care may be difficult $(12,13)$. The dual disorder clinic at the national drug dependence treatment centre in India (known as the dual diagnosis clinic) has been in operation since 2003. We hereby provide an analysis of the data of patients seeking consultation at this dual diagnosis clinic over the course of 12 years since its inception.

\section{Patients and Methods}

The present retrospective chart review was conducted on the patients' records from the dual diagnosis clinic 
of the national drug dependence treatment centre (NDDTC), All India institute of medical sciences (AIIMS), India. The NDDTC is a central government funded apex institute providing leadership in training, service provision, and research pertaining to de-addiction services in India (14). It has been designated as a regional learning centre by the united nations office on drugs and crime (UNODC) and the world health organization (WHO), and it has been recognized as the WHO collaborating centre on substance abuse. The centre offers inpatient and outpatient services, and provides pharmacotherapeutic, psychotherapeutic, rehabilitation, and outreach services to patients with substance use disorders.

The dual diagnosis clinic was established at the NDDTC, AIIMS in 2003. Patients with substance use disorders found to have co-morbid psychiatric disorders are referred to the dual diagnosis clinic for further comprehensive management. The cases referred to this weekly clinic are evaluated in detail by a resident trainee in psychiatry under the supervision of a qualified consultant. Information is gathered from the patient, family members, and previous case records. A diagnosis is then made as per ICD-10 criteria at the clinic.

For the purposes of the chart review, the records of patients registered in the dual diagnosis clinic since the time of its inception up until 2014 were reviewed. Extraction of information from the case records was conducted by three authors (SB, RG, NC). The demographic data that was extracted from the records included age, gender, marital status, educational attainment, current employment status, and current place of residence. Details of the substance use disorders and psychiatric disorders were ascertained from the case records. In case of doubts, clarifications were made after discussion with the other investigators. For simplicity of representation, the different psychiatric diagnostic groups were classified as follows: psychotic disorders, depressive disorders, bipolar affective disorder/mania, anxiety spectrum disorders (including obsessive compulsive disorder, dissociative disorder, and somatoform disorder), personality disorders, and others. Polysubstance dependence was considered to be present if there was dependence on three or more substances apart from tobacco.

\subsection{Data Analysis}

Statistical analysis was conducted using SPSS version 21 (IBM Corp, Armonk, NY). Only those cases that had at least one substance use disorder and an additional psychiatric disorder were selected for analysis. The demographic characteristics, substance use disorders, and psychiatric disorders were represented by descriptive statistics. The relationship between substances of use and psychiatric diag- nostic groups was assessed using a Chi-square test. Odds ratios with confidence intervals were computed to determine the strength of the relationship. The Chi-square test was applied to determine the trend over a period of five years. Missing value imputation was not conducted for the present study. A p value of less than 0.05 was considered significant, and the tests of inference were two tailed.

\section{Results}

The study included 492 patients registered in the dual diagnosis clinic over a period of 12 years (2003 to 2014). The socio-demographic and substance use characteristics of the patients are shown in table 1. The mean age of the patients was 33.3 years ( $S D=10$ years), with a range of 16 to 62 years. The sample was primarily comprised of males who were married and employed. About half of the sample was educated above the 10th grade. About one-fourth of the patients came from the same district (Ghaziabad), while about a third of the patients came from outside the National Capital Region of Delhi. The most common substance of dependence in this sample was tobacco, followed by alcohol and cannabis. Polysubstance dependence was present in 22 patients ( $4.5 \%$ of the sample).

The psychiatric diagnoses apart from substance use disorder included psychotic spectrum disorders $(n=191)$, depressive disorders $(n=135)$, bipolar affective disorder/mania $(n=98)$, anxiety disorders $(n=46)$, personality disorders $(\mathrm{n}=15)$, and others $(\mathrm{n}=7)$. Among the 191 patients with a diagnosis of psychosis, 78 (40.8\%) were deemed to have a clinical diagnosis of substance-induced psychosis. Among these 78 patients, psychosis was considered to be induced by cannabis in 66 patients, by alcohol in 5 patients, by opiates and inhalants in 4 patients ( 2 for each), and by indeterminate substances in 3 patients. Substance-induced depression was present in 9 out of 135 patients with depressive disorders (6.7\%), which was ascribed to alcohol in 8 patients and opiates in 1 patient. Substance-related bipolar disorder/mania was present in 10 patients $(10.2 \%$ of 98 patients with bipolar affective disorder/mania), with cannabis being considered the causative agent in 6, alcohol in 2, and the substance being indeterminate in 2 .

The relationship between the presence of a particular psychiatric disorder in conjunction with various substances of use is shown in Table 2. It was observed that psychosis had greater odds of being associated with cannabis dependence, and lower odds of being associated with alcohol or opiate dependence. Depressive disorders had greater odds of being associated with opiate and benzodiazepine dependence and lower odds of being related to 
Table 1. Characteristics of Patients Registered in the Dual Diagnosis Clinic from 2003 to 2014

\begin{tabular}{|c|c|}
\hline Variable & Values $^{\mathrm{a}}$ \\
\hline Age, $y$ & $33.3(10.0)$ \\
\hline \multicolumn{2}{|l|}{ Gender } \\
\hline Males & $480(97.6)$ \\
\hline Females & $12(2.4)$ \\
\hline \multicolumn{2}{|l|}{ Marital status $^{\mathbf{b}}$} \\
\hline Married & $300(62.5)$ \\
\hline Not married & $180(37.5)$ \\
\hline \multicolumn{2}{|l|}{ Education $^{c}$} \\
\hline Up to 10th grade & $235(49.6)$ \\
\hline Above 10th grade & $239(50.4)$ \\
\hline \multicolumn{2}{|l|}{ Employment status ${ }^{d}$} \\
\hline Employed & $295(62.8)$ \\
\hline Not employed & $175(37.2)$ \\
\hline \multicolumn{2}{|l|}{ Residence $^{e}$} \\
\hline Same district & $124(25.6)$ \\
\hline Other parts of Delhi and NCR & $182(37.6)$ \\
\hline Outside Delhi and NCR & $178(36.8)$ \\
\hline \multicolumn{2}{|c|}{ Substances being used in a dependent pattern } \\
\hline Tobacco & $355(72.2)$ \\
\hline Alcohol & $224(45.5)$ \\
\hline Cannabis & $172(35.0)$ \\
\hline Opiates & $160(32.5)$ \\
\hline Benzodiazepines & $50(10.2)$ \\
\hline Inhalants & $5(1.0)$ \\
\hline \multicolumn{2}{|l|}{ Number of substances being used } \\
\hline One & $131(26.6)$ \\
\hline Two & $271(55.1)$ \\
\hline Three & $70(14.2)$ \\
\hline Four & $17(3.5)$ \\
\hline Five & $3(0.6)$ \\
\hline Polysubstance dependence ${ }^{f}$ & $22(4.5)$ \\
\hline \multicolumn{2}{|l|}{ Psychiatric disorders } \\
\hline Psychosis & $190(38.7)$ \\
\hline Depressive disorders & $135(27.5)$ \\
\hline Bipolar affective disorders & $98(20.0)$ \\
\hline Anxiety disorders & $46(9.4)$ \\
\hline Personality disorders & $15(3.1)$ \\
\hline Others & $7(1.4)$ \\
\hline
\end{tabular}

Abbreviation: NCR, national capital region (India).

${ }^{a}$ Values are expressed as No. (\%) or mean (SD).

${ }^{\mathrm{b}}$ Missing data for 12 patients.

${ }^{\mathrm{c}}$ Missing data for 18 patients.

${ }^{\mathrm{d}}$ Missing data for 22 patients.

${ }^{\mathrm{e}}$ Missing data for 12 patients.

${ }^{\mathrm{f}}$ Dependence on 3 or more substances apart from tobacco. cannabis. Anxiety disorders had greater odds of being related to alcohol dependence and lower odds of being related to cannabis use disorder. Personality disorders or bipolar affective disorder/mania were not associated with the use of particular substances in the present sample.

The time trends of the various substance uses and psychiatric disorders seen in the dual diagnosis clinic are shown in Figure 1 (A and B). A significant change in the time trend over the 12 years was observed for the proportion of patients with opioid dependence syndrome (ptrend $=0.015$ ); cannabis dependence syndrome (ptrend $<0.001$ ) and benzodiazepine dependence syndrome (ptrend $=0.039$ ) were observed over the twelve years. Similarly, a significant linear trend of change over 12 years was observed for the proportion of patients diagnosed with psychotic disorders (ptrend $=0.002$ ).

Figure 1. Time Trends in Proportion of Patients With Different A, Substance Use Disorders; B, Psychiatric Disorders in Consultation With the Dual Diagnosis Clinic over the Twelve Year Period (2003 - 2014)

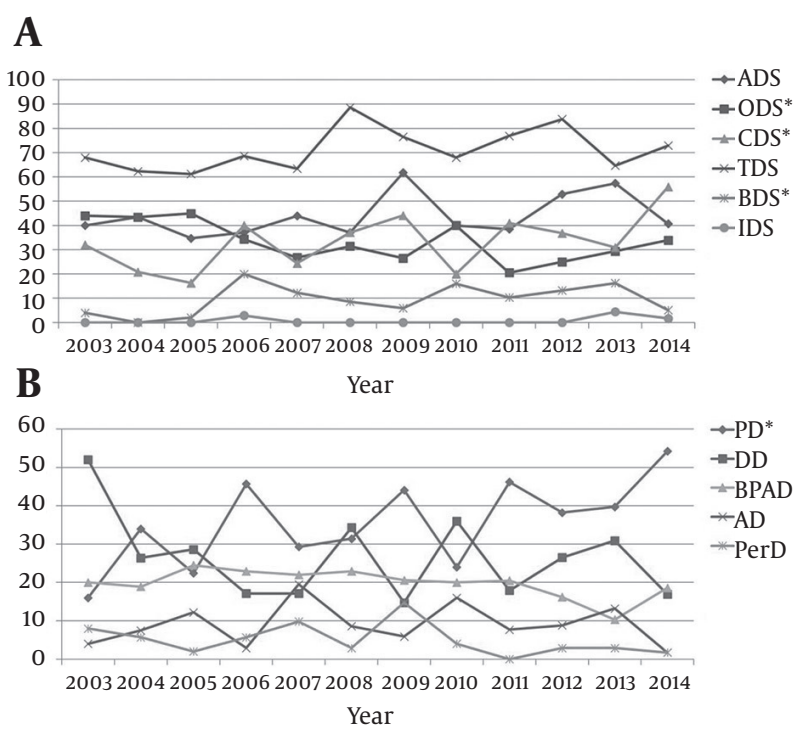

ADS, alcohol dependence syndrome; ODS, opioid dependence syndrome; CDS, cannabis dependence syndrome; TDS, tobacco dependence syndrome; BZD, benzodiazepine dependence syndrome; IDS, inhalant dependence syndrome; PD, Psychotic disorders; DD, depressive disorders; BPAD, bipolar affective disorder; AD, anxiety disorders; PerD, personality disorders. *Significant linear time trend.

\section{Discussion}

The demographic statistics of the sample in the current study were largely similar to other studies from the region and the centre, with males substantially outnumbering females (15-19). This observation has been made in the previous studies from the centre and might be due to 
Table 2. Relationship Between Psychiatric Disorder and Substance Use Disorder ${ }^{\mathrm{a}}$

\begin{tabular}{|c|c|c|c|c|c|}
\hline Psychiatric Disorders & Tobacco & Alcohol & Cannabis & Opiate & Benzodiazepine \\
\hline Psychosis & $1.37(0.94-2.06)$ & $0.43(0.29-0.62)^{b}$ & $4.82(3.24-7.17)^{\mathrm{b}}$ & $0.64(0.43-0.95)^{b}$ & $0.65(0.34-1.22)$ \\
\hline Depressive disorder & $0.76(0.50-1.18)$ & $1.36(0.92-2.03)$ & $0.20(0.12-0.35)^{\mathrm{b}}$ & $1.80(1.19-2.72)^{\mathrm{b}}$ & $1.90(1.04-3.47)^{b}$ \\
\hline BPAD/Mania & $0.90(0.55-1.46)$ & $1.54(0.99-2.39)$ & $1.16(0.74-1.84)$ & $0.95(0.59-1.53)$ & $0.63(0.27-1.44)$ \\
\hline Anxiety disorder & $0.87(0.45-1.69)$ & $1.98(1.07-3.69)^{b}$ & $0.11(0.04-0.37)^{b}$ & $0.90(0.46-1.74)$ & $1.68(0.71-3.99)$ \\
\hline Personality disorder & $1.06(0.33-3.40)$ & $1.05(0.37-2.94)$ & $0.28(0.06-1.25)$ & $1.04(0.35-3.09)$ & $0.62(0.08-4.85)$ \\
\hline
\end{tabular}

Abbreviation: BPAD, bipolar affective disorder.

${ }^{a}$ Shown as odds ratios with confidence intervals.

${ }^{\mathrm{b}}$ Significant findings $(\mathrm{P}<0.05)$.

the lower prevalence of substance use disorders among women in India, and the specific barriers to seeking treatment experienced by them $(20,21)$. The age range of the patients also displayed wide variation, suggesting that the clinic catered to a wide range of the patient population. The finding of tobacco being the most common substance of use was expected given the high general prevalence of tobacco use, especially among the substance using population (22-24). The high rates of alcohol and opiate use disorders being encountered in this study also reflect the general profile of substance users in the region (19).

The study suggested that psychotic disorders comprised the largest proportion of psychiatric disorders encountered in the clinic. Moreover, a significant trend of increase in the proportion of patients with psychotic disorders was observed over the past three years. Since the present study was conducted in a tertiary care de-addiction facility, referral bias might have led to over-representation of the psychotic disorders. Usually, those patients who demonstrate clear observable behavioural disturbances are referred to the specialized clinic. Patients with psychotic dual diagnoses pose specific challenges for management, which the routine de-addiction services are not able to cater to.

Based upon clinical diagnostic interviews, about forty percent of the psychotic disorders were considered as substance-induced. Cannabis was the substance most commonly associated with induction of psychotic symptoms, followed by less frequent reports of alcohol, opiate, and solvent abuse-induced psychosis. This is congruent with previous literature where cannabis has been associated with the induction of psychosis among the vulnerable population $(25,26)$. Cannabis was also associated with the emergence of manic symptoms, while alcohol was associated with the induction of depression. These findings are similar to those reported from other parts of the world (27, 28). It must be remarked that the diagnosis of substanceinduced disorder was based upon empirical evidence from the history and course of the illness, and in some cases, complete certainty could not be achieved.

In the specific sample of dual diagnosis patients, specific associations were found between the substance of abuse and the presence of specific psychiatric disorders. Cannabis was associated with the emergence of psychotic disorders, the mechanisms of which might have several facets $(29,30)$. The likelihood of a psychotic patient consuming alcohol or opiates was lower, probably a reflection of cannabis playing a prominent role in the genesis of psychosis. Similarly, use of opiates and benzodiazepines was associated with the presence of depressive disorders and alcohol use with anxiety disorders, while the presence of cannabis use was associated with lower rates of the occurrence of anxiety and depressive disorders. This further lends credence towards the specificity of the relationship between particular kinds of substance use and different psychiatric disorders $(31,32)$. It can be speculated that patients with substance use disorder develop specific psychiatric disorders as a consequence of their particular substance use. Conversely, some patients might have chosen particular substances to self-medicate their symptoms. The directionality of the association, however, cannot be ascertained from the present study, but it is likely that both explanations might hold true to some extent.

The findings of this study need to be interpreted in light of certain limitations. The study was retrospective in nature and the findings were restricted to the data that could be retrieved from the records. Furthermore, the findings represent those treated at a specialized clinic in a tertiary-care centre. The association of the substance use disorders and psychiatric disorders was based upon the limited sample of those registered at a dual diagnosis clinic.

\subsection{Conclusions}

The findings of the study suggest that a wide variety of cases can be treated by a dual diagnosis clinic attached to 
de-addiction facilities. Such a clinic would need minimal investment of resources in terms of personnel and physical infrastructure. Still, the benefits of such a clinic extend beyond integrated care delivery for dual disorders, as such settings also offer opportunities for the training of specialists, the development of protocols for the management of concurrent disorders, and the provision of focused care for individuals at a higher risk of relapse. Further studies may attempt to address the service provision barriers of patients with a dual diagnosis, and reveal the outcomes of patients who are provided care in such specialized clinics.

\section{Footnote}

Authors' Contribution: Yatan Pal Singh Balhara was involved in the study conceptualization, planning, methodology design, analysis, writing of the manuscript, and the review; Siddharth Sarkar was involved in data analysis, and the writing and review of manuscript; Sagar Chandra Bera, Nishtha Chawla, and Rishi Gupta were involved with data acquisition and review of the manuscript; Rakesh Lal was involved in the review of the manuscript.

\section{References}

1. Conway KP, Compton W, Stinson FS, Grant BF. Lifetime comorbidity of DSM-IV mood and anxiety disorders and specific drug use disorders: results from the National Epidemiologic Survey on Alcohol and Related Conditions. JClin Psychiatry. 2006;67(2):247-57. [PubMed: 16566620].

2. Grant BF, Stinson FS, Dawson DA, Chou SP, Dufour MC, Compton W, et al. Prevalence and co-occurrence of substance use disorders and independent mood and anxiety disorders: results from the National Epidemiologic Survey on Alcohol and Related Conditions. Arch Gen Psychiatry. 2004;61(8):807-16. doi: 10.1001/archpsyc.61.8.807. [PubMed: 15289279].

3. Kessler RC. The epidemiology of dual diagnosis. Biol Psychiatry. 2004;56(10):730-7. doi: 10.1016/j.biopsych.2004.06.034. [PubMed: 15556117].

4. Basu D, Gupta N. Management of "dual diagnosis" patients : consensus, controversies and considerations. Indian J Psychiatry. 2000;42(1):34-47. [PubMed: 21407906].

5. Morojele NK, Saban A, Seedat S. Clinical presentations and diagnostic issues in dual diagnosis disorders. Curr Opin Psychiatry. 2012;25(3):1816. doi: 10.1097/YCO.0b013e328351a429. [PubMed: 22449761].

6. Cridland EK, Deane FP, Hsu CI, Kelly PJ. A comparison of treatment outcomes for individuals with substance use disorder alone and individuals with probable dual diagnosis. Int J Ment Health Addict. 2012;10(5):670-83.

7. Drake RE, Essock SM, Shaner A, Carey KB, Minkoff K, Kola L, et al. Implementing dual diagnosis services for clients with severe mental illness. Psychiatr Serv. 2001;52(4):469-76. doi: 10.1176/appi.ps.52.4.469. [PubMed: 11274491].

8. Kelly TM, Daley DC, Douaihy AB. Treatment of substance abusing patients with comorbid psychiatric disorders. Addict Behav. 2012;37(1):1124. doi: 10.1016/j.addbeh.2011.09.010. [PubMed: 21981788].

9. Baigent M. Managing patients with dual diagnosis in psychiatric practice. Curr Opin Psychiatry. 2012;25(3):201-5. doi: 10.1097/YCO.0b013e3283523d3d. [PubMed: 22449766].
10. Murthy P, Chand P. Treatment of dual diagnosis disorders. Curr Opin Psychiatry. 2012;25(3):194-200. doi: 10.1097/YCO.0b013e328351a3e0. [PubMed: 22395768].

11. Sarkar S, Katana S, Mattoo SK. Managing dual diagnosis patients with psychosis and substance use disorders. J Ment Heal Hum Behav. 2012;17:25-38.

12. Basu D, Sarkar S, Mattoo SK. Psychiatric comorbidity in patients with substance use disorders attending an addiction treatment center in India over 11 years: Case for a specialized "dual diagnosis clinic". JDual Diagnos. 2013;9(1):23-9.

13. Mattoo SK, Singh SM, Sarkar S. De-addiction services in India. Springer; 2015.

14. Ray R, Dhawan A, Chopra A. Addiction research centres and the nurturing of creativity: National Drug Dependence Treatment Centre, India-a profile. Addiction. 2013;108(10):1705-10. doi: 10.1111/j.13600443.2012.04046.x. [PubMed: 23075217].

15. Balhara YP, Jain R. A urinalysis-based study of buprenorphine and non-prescription opioid use among patients on buprenorphine maintenance. J Pharmacol Pharmacother. 2012;3(1):15-9. doi: 10.4103/0976-500X.92496. [PubMed: 22368411].

16. Balhara YP, Jain R. Cannabis use among opioid-dependent individuals on opioid substitution therapy. J Pharmacol Pharmacother. 2014;5(3):203-5. doi: 10.4103/0976-500X.136106. [PubMed: 25210401].

17. Nebhinani N, Sarkar S, Gupta S, Mattoo SK, Basu D. Demographic and clinical profile of substance abusing women seeking treatment at a de-addiction center in north India. Ind Psychiatry J. 2013;22(1):12-6. doi: 10.4103/0972-6748.123587. [PubMed: 24459367].

18. Varshney M, Gupta R, Balhara YP. Yes, India has done it: Decriminalization of suicide in India. Asian J Psychiatr. 2015;17:103. doi: 10.1016/j.ajp.2015.07.005. [PubMed: 26253554].

19. Balhara YP, Mishra A, Sethi H, Ray R. A retrospective chart review of treatment seeking middle aged individuals at a tertiary care substance use disorder treatment centre in North Part of India over five successive years: findings from drug abuse monitoring system. ScientificWorldJournal. 2013;2013:316372. doi: 10.1155/2013/316372. [PubMed: 24288477].

20. Kermode M, Songput CH, Sono CZ, Jamir TN, Devine A. Meeting the needs of women who use drugs and alcohol in North-east India - a challenge for HIV prevention services. BMC Public Health. 2012;12:825. doi: 10.1186/1471-2458-12-825. [PubMed: 23013114].

21. Murthy P, Manjunatha N, Subodh BN, Chand PK, Benegal V. Substance use and addiction research in India. Indian J Psychiatry. 2010;52(Suppl 1):S189-99. doi: 10.4103/0019-5545.69232. [PubMed: 21836677].

22. Sarkar S, Nebhinani N, Gupta S, Parakh P, Basu D. Pathways of progression from one substance use to another in treatment seekers. Drug Alcohol Depend. 2014;140:e195-6.

23. Jain R, Balhara YP, Jhanjee S, Sethi H. Concordance between urinary cotinine levels and self-reported tobacco use among drugdependent persons: a pilot study. Subst Abus. 2012;33(2):99-102. doi: 10.1080/08897077.2011.630947. [PubMed: 22489581].

24. Quraishi R, Jain R, Balhara YP. Profile of nicotine use among alcohol dependent patients visiting a tertiary care center in north India. Indian J Psychol Med. 2014;36(2):174-8. doi: 10.4103/0253-7176.130987. [PubMed: 24860220].

25. Aggarwal M, Banerjee A, Singh SM, Mattoo SK, Basu D. Substanceinduced psychotic disorders: 13-year data from a de-addiction centre and their clinical implications. Asian J Psychiatr. 2012;5(3):220-4. doi: 10.1016/j.ajp.2011.11.008. [PubMed: 22981049].

26. Parakh P, Basu D. Cannabis and psychosis: have we found the missing links?. Asian J Psychiatr. 2013;6(4):281-7. doi: 10.1016/j.ajp.2013.03.012. [PubMed: 23810133].

27. Gibbs M, Winsper C, Marwaha S, Gilbert E, Broome M, Singh SP. Cannabis use and mania symptoms: a systematic review and metaanalysis. J Affect Disord. 2015;171:39-47. doi: 10.1016/j.jad.2014.09.016. [PubMed: 25285897]. 
28. Schuckit MA. Alcohol and depression: a clinical perspective. Acta Psychiatrica Scandinavica. 1994;89(s377):28-32.

29. Damjanovic A, Pantovic M, Damjanovic A, Dunjic-Kostic B, Ivkovic M, Milovanovic S, et al. Cannabis and psychosis revisited. Psychiatria Danubina. 2015;27(1).

30. Degenhardt L, Hall W. Cannabis and psychosis. Curr Psychiatry Rep. 2002;4(3):191-6. [PubMed: 12003681].
31. Khantzian EJ. The self-medication hypothesis of substance use disorders: a reconsideration and recent applications. Harv Rev Psychiatry. 1997;4(5):231-44. doi: 10.3109/10673229709030550. [PubMed: 9385000].

32. Mueser KT, Drake RE, Wallach MA. Dual diagnosis: a review of etiological theories. Addict Behav. 1998;23(6):717-34. [PubMed: 9801712]. 